\title{
Editorial 2015
}

\section{F. Duparc $\cdot$ B. Grignon}

Published online: 10 January 2015

(C) Springer-Verlag France 2015

Dear clinical anatomists and researchers,

On behalf of the editorial board of Surgical and Radiologic Anatomy, we wish all of you a very nice and happy New Year 2015. Thanks to the continuous and hard job of the complete team of associate editors and to the 822 reviewers who completed reviews in 2014, and to our publishing managers, we could face a very important increasing of the number of submitted manuscripts: 669 new manuscripts were received within last year; this represents $27 \%$ of augmentation. The new Impact Factor calculated of our journal continued also to progress, and is now 1.333 (2 years) and 1.212 (5 years).

The clinical anatomy and the related research will be the center of interest of the International Congress of Clinical Anatomy that will be held in Rouen (France) in 2015 June 24th-27th. We hope this joint meeting (European Association, British Association, and Spanish Association for Clinical Anatomy) will be the place where researchers, anatomists and clinicians will get time to exchange and communicate knowledge about anatomy and education.

F. Duparc $(\bowtie) \cdot$ B. Grignon

Nancy, France

e-mail: fabrice.duparc@univ-rouen.fr 